\title{
ACTITUDES INTELECTUALES FRENTE \\ A LAS CONDICIONES DE TRABAJO \\ EN LAS MINAS DE ALMADEN 1760-1860
}

RAFAEL DOBADO GONZALEZ

Universidad Complutense

\section{Introducción}

El presente artículo pretende mostrar el cambio experimentado durante el período 1760-1860 por las actitudes intelectuales dominantes en relación con los aspectos sociales más estrechamente conectados con el proceso productivo del mercurio en las Minas de Almadén.

En el transcurso de esos cien años fue publicado un cierto número de obras acerca de las actividades desarrolladas en el citado establecimiento minero. Junto a ensayos históricos, técnicos y económicos se redactan otros de carác. ter médico, moral o religioso. Unidos a la documentación elaborada por las propias Minas, permiten conocer los dos puntos en que aquí nos centraremos: de una parte, el proceso de trabajo y sus consecuencias sociales; de otra, las líneas maestras que presiden el pensamiento de los autores de esa heterogénea masa documental.

Como puede imaginarse, las conexiones entre uno y otro punto son múltiples, dando lugar a la aparición de la estructura compleja pensamiento/realidad socioeconómica cuyo análisis intentamos.

La prosecución ininterrumpida del proceso productivo que permitía la obtención del azogue a partir del cinabrio existente en el subsuelo de Almadén y sus alrededores planteaba numerosas exigencias sociales. Las resumiremos en la aceptación por los trabajadores del conjunto de normas que, regulando el uso de objetos, medios y fuerza de trabajo, codificaban técnica y socialmente el proceso de trabajo. Como consecuencia de esta codificación, surge un orden productivo en ausencia del cual resultaría imposible organizar a miles de trabajadores («empleados» - funcionarios-y jornaleros «de continuo» y «temporeros») en un proceso compuesto por fases diferentes (excavación, fortificación, desagüe, extracción, fundición, transporte, almacenamiento y otras de menor entidad) desarrolladas en diversos espacios (minas, hornos y talleres). El orden productivo requiere disciplina '. Esta se instrumentaba median-

' En el texto se emplea este término siguiendo la definición propuesta por Gaudemar (1981a y b). 
te una reglamentación que comprendía desde las cuestiones estrictamente técnicas (sistema global de laboreo de los yacimientos, manera de practicar un barreno) hasta las sociales (formas retributivas, modalidades de asistencia a los enfermos, heridos, ancianos, viudas y huérfanos), pasando por otras de calificación menos precisa (distribución de los trabajadores entre las diferentes faenas exteriores e interiores, sistema jerárquico, mecanismos de ascenso profesional). Así, recursos naturales, instrumentos y hombres formaban parte de un entramado de relaciones cuya razón de ser era la de propiciar la saca anual de azogue. Al constituir el mercurio un input insustituible en el procedimiento de la amalgamación, gracias al cual era posible la explotación rentable de la mayor paite de los minerales de plata americanos, la producción de Almadén resultaba trascendental para la Real Hacienda. De ahí la importancia del orden productivo en las Minas. Orden productivo que, junto al orden social que lo enmarca -exponentes ambos de las estructuras socioeconómicas de la España de la época-, era cotidianamente cuestionado por los mineros. Más adelante volveremos sobre estos temas.

Por lo que respecta a las consecuencias sociales, nos limitaremos a considerar las condiciones materiales de vida ${ }^{2}$ y la «economía moraln de los trabajadores de las Minas. Para entender unas y otra resulta necesario conocer previamente una de las principales características del proceso productivo del azogue: sus nocivos efectos sobre la «economía orgánica» de los mineros. El deterioro del estado sanitario de la población trabajadora causado por los ac. cidentes y, en especial, por las enfermedades profesionales, es un factor que contribuye, tal vez más que ningún otro, a explicar las especificidades del modelo de uso de la fuerza de trabajo en las Minas de Almadén. Además de su interés social como indicador de las adversas condiciones biológicas que presidían la vida de la generalidad de los mineros, los problemas relacionados con la «economía orgánica» revestían una no menor importancia económica. Los altos requerimientos de mano de obra, la insuficiencia de oferta de trabajo registrada hasta bien entrada la segunda mitad del siglo xviı, la política poblacionista (exenciones militares y fiscales, sorteo anual de parcelas, asistencia médica y abastecimiento de granos), la distribución rotativa de trabajadores en el interior de las minas, la contratación sistemática de «jornales de saneamiento", la suspensión de los trabajos con la llegada del verano y su reanudación en otoño, el valor nominal de los salarios, por citar sólo algunos, son hechos cuya explicación reside en las dificultades que unos elevados indi-

: Por este término compuesto deben entenderse la agregación en un conjunto heterogéneo de los resultados no ideológicos que para la población de Almadén se derivaban del proceso de trabajo en las Minas y del consumo de los bienes y servicios que permitían la reproducción de la fuerza de trabajo. 
ces de mortalidad y morbilidad interponian a la reproducción física de la fuerza de trabajo.

Dada la ausencia, durante el periodo 1760-1860, de innovaciones significativamente beneficiosas para la "economía orgánica» de los mineros, ésta, ceteris paribus, era una función creciente de la oferta de trabajo y decreciente de la producción.

En otro orden de cosas, la «economía orgánica» evidencia una valoración social de la vida humana, esto es, resulta de una elección social entre mercurio y salud. Todo parece indicar que, en el transcurso de la centuria estudiada, la sociedad española, o, más exactamente, los sujetos y grupos que ostentaban el poder, se inclinaron de manera permanente por el codiciado metal.

Por otra parte, las posibilidades de consumo de los mineros también forman parte de las consecuencias sociales conocidas del proceso productivo ${ }^{3}$. En estrecha dependencia del precio de los productos agrarios, dicho indicador del nivel material de vida de los trabajadores experimentó profundas modificaciones entre 1760 y 1835 . Al margen de las fluctuaciones interanuales causadas por las variaciones del precio de trigo, pueden detectarse tendencias a largo plazo. Así, antes de 1782, el salario real creció; disminuyó considerablemente desde 1784 a 1818, haciendo repetidas veces su aparición agudas crisis de subsistencia; después de 1818 se asiste a su continuo incremento ${ }^{4}$.

El concepto de «economía moral», tomado de E. J. Thompson ${ }^{5}$, resulta también adecuado aquí para designar el trasfondo ideológico de la actitud del "mineraje» frente a su participación en el proceso productivo. Regulando la conducta cotidiana del colectivo minero y legitimando sus acciones de protesta, puede observarse un código de comportamiento profundamente asumido, una «economía moral». Sus principios básicos definían un consenso general relativo al significado socioeconómico concreto de la condición de minero del azogue en virtud del cual era interpretada la realidad circundante. Un amplio número de aspectos básicos del régimen laboral instaurado en las Minas (el modelo de relaciones contractuales distinto del plenamente capitalista, la alternancia del trabajo minero y agrario, el reparto equitativo del trabajo, la oferta de «jornales de saneamiento», el grado «natural» de esfuerzo) pasaban por el filtro de la «economía moral». La protesta individual o colectiva de los

Debe subrayarse que la subsistencia de las familias no provenía exclusivamente de los ingresos salariales de sus miembros activos. En una proporción indeterminada y variable, la reproducción de la fuerza de trabajo se llevaba a cabo mediante actividades económicas ajenas al mercado. La evolución de las posibilidades de consumo descrita en el texto refleja la confrontación de los salarios monetarios y el precio del trigo. En mi tesis, actualmente en fase de elaboración, se aborda con cierto detalle el papel desempeñado por el mercado, tanto de trabajo como de bienes y servicios, en la subsistencia de las familias en una economía no capitalista.

- Un tratamiento más detenido del tema sc encuentra en Dobado (1982), pp. 369-382.

"Vease Thompson (1979). 
trabajadores surgía cuando alguno de estos principios era transgredido más allá de cierto límite por las decisiones de la dirección o la superintendencia. Estas transgresiones tenían lugar cuando los apuros presupuestarios ( $\tan$ frecuentes en este período), las alteraciones más o menos duraderas de la oferta de trabajo o las decisiones demasiado ambiciosas respecto al volumen de la saca anual de azogue, sometían a tensiones adicionales al delicado equilibrio sobre el que reposaba el proceso de producción. Roto el consenso, el orden productivo sólo podía lograrse mediante la represión.

Para finalizar esta introducción, describiremos brevemente las características de las obras que, a nuestro juicio, mejor manifiestan el cambio operado entre 1760 y 1860 por las actitudes intelectuales dominantes en relación con los aspectos sociales antes comentados. Redactadas por miembros cualificados de la intelectualidad orgánica del régimen absolutista, unas, y del capitalismo liberal, otras, pretenden describir y/o modificar la realidad imperante. Sus contenidos positivo y normativo permiten detectar la modificación experimentada por las preocupaciones de sus autores, así como por las soluciones por ellos propuestas. Para simplificar la exposición, agruparemos las obras en dos corrientes de pensamiento, calificadas de «antigua» y «moderna». Como exponente de la primera contamos con el Plan de un nuevo gobierno eclesiástico necesario y provechoso a la Villa de Almadén, e intereses del Rey, del eclesiástico Clemente José de Ortuño, y con el Catastrophe morboso de las Minas Mercuriales de la Villa de Almadén del Azogue, del médico José Parés y Franqués. Los representantes del pensamiento «moderno» son la Memoria sobre las Minas de Almadén y Almadenejos, de los ingenieros de minas Fernando Bernáldez y Ramón Rúa, y la Memoria sobre azogues, del también ingeniero de minas Luis María Sánchez-Molero. En síntesis, el contenido de las citadas obras es el siguiente: el Plan... constituye un intento de favorecer el orden productivo desde posiciones político-ideológicas netamente absolutistas, pretendiendo estrechar la colaboración entre el «gobierno temporal» y el «gobierno espiritual» mediante una más intensa instrucción religiosa de los mineros; el Catastrophe..., un tratado sobre las enfermedades «médico-morales» de los trabajadores de las Minas, expone la preocupación de una personalidad filantrópica por la magnitud de los costes sociales del proceso productivo; por último, las memorias de los ingenieros representan dos proyectos casi idénticos de "reconversión» de las Minas tendentes a recuperar la perdida competitividad internacional del mercurio español, incorporando también una cierta visión de los problemas sociales y unas propuestas concretas de solución de los mismos que traducen la confianza en el progreso técnico propia de la Europa del siglo xix. Razones de espacio obligan a que el tratamiento de las citadas obras se limite a encontrar un hilo argumental a través del cual puedan apreciarse las diferencias entre el "pensamiento antiguo» y el «pensamiento mo- 
derno» en lo tocante a sus actitudes respectivas frente a los aspectos socioeco. nómicos del trabajo en las Minas de Almadén.

\section{El «Plan...» de Ortuño}

El título completo de este opúsculo, aparecido como manuscrito en 1804, Plan de un nuevo gobierno eclesiástico necesario y provechoso a la Villa de Almadén, e intereses del Rey, refleja fielmente el propósito perseguido con su redacción. Sin embargo, no será infructuoso avanzar en el análisis de dicho título.

En primera instancia, el Plan... expresa un cierto proyecto novedoso acerca de un sujeto doble, compuesto por la villa de Almadén y los intereses reales. Si al primer componente le dotamos de su auténtico contenido, nos encontraremos con el colectivo humano representado por los habitantes de Almadén, colectivo cuya existencia en el transcurso de la historia está estrechamente ligada a las minas de cinabrio explotadas desde antiguo en esa localidad y sus alrededores. $\mathrm{Si}$, procediendo de manera similar, avanzamos en la comprensión del significado del segundo componente, llegaremos a un resultado idéntico al anterior. La condición de propiedad real de esas minas nos conduce a contemplarlas como los representantes más inmediatos de los intereses regios en el discurso de Ortuño.

Por tanto, el Plan... remite a las Minas. Esta idea gana en verosimilitud cuando se conoce el nombre de la persona que encargó su redacción, Tomás Pérez de Estala, superintendente de las Minas de Almadén durante dos breves períodos de tiempo.

Tras dicha "empresa» minera hallaremos un microcosmos particular, una realidad social específica formada por individuos trabajando para un patrón, el Rey, del que también son súbditos, y surgida en torno a unas actividades técnico-económicas precisas. Realidad social que, siendo parte integrante de una unidad más amplia, cual es la sociedad española del Antiguo Régimen, ha sido individualizada, aislada de! conjunto por Ortuño, para convertirse en el verdadero sujeto de su proyecto. Y que, además, al ser separada de su contexto global, goza, a juicio de Ortuño, de una entidad propia lo suficientemente diferenciada de otras como para convertirse en el destinatario exclusivo del experimento social por él propuesto.

En otras palabras, el Plan... carece de una lectura independiente de las relaciones sociales establecidas entre los agentes que intervenían en el proceso productivo. Por esta razón, el Plan... se ocupará primordialmente de dos tipos de relaciones: las de los habitantes de Almadén entre sí y las de éstos con el monarca. Habida cuenta del doble papel desempeñado por el Rey, suprema 
instancia política y económica a la vez, el Plan..., en definitiva, nos habla de unas relaciones sociales, políticas y económicas específicas en el seno de la sociedad española de comienzos del siglo xix.

El objeto reconocido del Plan... está bien delimitado. Se trata de incrementar el espacio ocupado por la religión católica en Almadén, tanto en la vida pública como en las conciencias individuales, y de reducir el coste económico de la oferta de los diferentes servicios religiosos. Ortuño lo expresa en los siguientes términos:

... restablecer el culto exterior a que es tan acreedor la Majestad de Nuestro Dios; el modo de dar a los hombres el pasto espiritual; las instrucciones necesarias para que rindan al mismo Dios el culto interior; y formar sus corazones, y consolidarlos en las máximas sagradas de la Religión Cristiana...: Y que todo este Plan pudiese realizarse sin el dispendio, que en el día sufre el Real Erario ${ }^{6}$.

Este propósito manifiesto no es sino un medio que, en realidad, apunta hacia un objetivo claramente político, pero que, dadas las relaciones económicas existentes entre los habitantes de Almadén y su soberano-patrón, se convierte también en económico. Ortuño concibe la religión como el instrumento más eficaz para «... hacer a todos buenos ciudadanos, fieles y leales vasallos..." ${ }^{7}$, es dècir, para lograr una socialización no conflictiva. No resulta difícil comprobar que el auténtico objetivo económico del Plan... excede al ámbito relativamente modesto de una mera propuesta tendente a disminuir los gastos causados por la asistencia religiosa a la población. Simple cuestión de proporciones, dicha cifra era insignificante comparada con las abultadas nóminas de las Minas. Ortuño, mucho más ambicioso, pretende contribuir desde la esfera de lo ideológico al funcionamiento ordenado del proceso productivo. Para ello, el discurso religioso resultará ser una ayuda inestimable. Para nuestro presbítero, la religión desempeña un papel fundamental en el correcto ordenamiento de la sociedad. A este respecto, no puede ser más explícito:

Un Estado no puede subsistir sin la obediencia a las leyes; pero ésta no se puede persuadir a los ciudadanos, sino por medio de la Religión, y sus Ministros. Es tal la conexión admirable, que estableció la Providencia, entre la Religión, y la Sociedad, que la conservación de los Estados depende necesariamente de las leyes divinas ${ }^{8}$.

- Ortuño (1804), p. 3.

Ibidem.

- Ibidem, p. 5. 
Pero el interés de la obra de Ortuño no se limita a constituir un ejemplo arquetípico de defensa a ultranza del Estado absolutista, o a exponer, casi diría que cándidamente, la articulación de las instancias superestructurales del Antiguo Régimen, porque, además, tendrá presente la utilidad en el terreno de las actividades económico-productivas de la intensificación de la presencia religiosa por él propugnada. Para Ortuño, la capacidad disciplinaria de la religión católica en este último ámbito no es menos patente. Las Minas, ¿cómo no?, acaban sirviendo de demostración a su tesis. Dirigiéndose a Pérez de Estala, escribe Ortuño:

... pero como buen cristiano, conoció, y conoció muy bien, que sin restablecer el culto a Dios, y formar los corazones, con las Sagradas máximas de su verdadera, y Santa Religión, era imposible organizar, y poner en el mejor pie todos los ramos, que abraza tan útil establecimiento ${ }^{9}$.

De las palabras de Ortuño se infiere que el correcto funcionamiento de las Minas exigía reforzar la instrucción religiosa de los mineros. Al mismo tiempo, se da a entender que la superintendencia distaba de haber conseguido establecer un orden productivo satisfactoric. Así hemos llegado a conocer la causa que motivó la redacción del Plan....

La realidad social específica surgida del comportamiento colectivo de la población de Almadén atentaba contra los intereses económicos directos de la Monarquía y contra los principios simbólicos del régimen absolutista:

... que los enfermos se vean sin asistencia; los mat:imonios desunidos: los hijos de familia. fuera le la casa de sus padres; los novios, cun entera libertad; los amancebamientos públicos; los rón : irautes a la Real Hacienda, continuados, y aún me atrevo " ciecir an+arizados, y aprobados. Basta, Señor, no debo aclaiüh mas: Sencjante subversión de principios e ideas no se le oculta a la penetración de V. S. que los ha notado por experiencia y conoce como yo, que este, transtorno ocupa ya todo su apogeo o mayor incremento... ${ }^{10}$.

Este cuadro de «subversión de principios e ideas» surge como consecuencia del incumplimiento de sus tareas por parte del clero local. Para llegar a esta conclusión, Ortuño se ha visto obligado a superar ciertos reflejos corporativos:

Ibidem, p. 2.

10 Ibidem, pp. 11 y 12. 
A la verdad Señor, me es sumamente sensible, y doloroso, haber de declamar contra la desidia, poco celo, abandono, y olvido de los deberes más sagrados de mis hermanos, y compañeros, en el ministerio...".

Sin una eficaz actuación mediadora del estamento religioso, el orden «natural» de la sociedad es puesto en peligro, pues la «innata maldad de los seres humanos" no resulta convenientemente corregida. Sólo con una instrucción constante en los "principios de la religión natural, corroborados por la ley evangélica", los sacerdotes cumplen con la misión que tienen asignada e «impresionan en el corazón débil y flaco de los hombres». Una vez más, Or tuño expone los resultados del abandono de los hombres a su propia suerte:

... si todo un pueblo, cuyos habitantes se dejan llevar de lo que les dictan sus pasiones, no oye otra voz, que los gritos de la concupiscencia, ambición y desorden; si obran conducidos por las tinieblas de la ignorancia, compañera inseparable de la naturaleza corrompida; este pueblo, lejos de ser feliz, labrará a cada paso su desgracia, y se precipitará de abismo en abismo: si este pueblo, tan propenso al mal, no tiene un pastor instruido y celoso, que junto con los demás sacerdotes enseñe en el templo y fuera de él, y le haga conocer sus verdaderos deberes para con Dios, para con el prójimo, y para con su soberano, este pueblo jamás prosperará, ni para sí, ni para su legítimo Señor ${ }^{12}$.

Ortuño, una vez demostradas las limitaciones de los mecanismos disciplinarios externos a los individuos, se muestra partidario de centrar los esfuerzos en la modificación de la constitución más íntima de los habitantes de Almadén. Su propuesta consiste en colaborar con el poder político y económico mediante la creación de una disciplina persuasiva que surgiría tras arraigar los valores morales favorables al orden productivo en lo más profundo de las conciencias de los mineros. En relación con este tema, escribe:

... muchos de estos excesos es verdad se castigan, y corrigen por el Gobierno, pero no es bastante como V. S. lo sabe; es necesario que el gobierno temporal sea auxiliado y sostenido por el gobierno espiritual y que procedan de acuerdo el uno con el otro... ${ }^{13}$.

"Ibidem, p. 4.

"Ibidem, p. 9.

"Ibidem, p. 13. 
En definitiva, se trataba de complementar los mecanismos disciplinarios disponibles por la superintendencia operando desde el exterior del proceso productivo. No andaba del todo desencaminado Ortuño, pues en algunas partes de Europa resultaban patentes los logros de las tendencias religiosas originadas por la reforma protestante como instrumentos de control social. Pero sólo tiene en cuenta una de las facetas del problema que pretende resolver. Están fuera de toda duda las contribuciones de la religión y la escuela al objetivo disciplinario implícito en la producción industrial. Sin embargo, fue la fábrica mecanizada el elemento clave a la hora de explicar la creación del tipo humano necesario al orden productivo industrial, el obrero fabril forzosamente activo, probo y dócil. Figura social cuya consecución fue uno de los empeños más firmemente perseguidos por esos empresarios que, en la época de aparición del Plan..., comenzaban a ver consolidada su posición en Gran Bretaña.

Para Marglin, «... la fábrica puso punto final a la "falta de probidad" y a la "pereza" "14. Antes que por razones de superioridad tecnológica, la fábrica se impuso por su eficacia para hacer desaparecer los «vicios» de la incipiente clase ob:era británica. Pues bien, como antes veíamos, «vicios» similares son detectados por Ortuño formando parte de la «economía moral» de los mineros de Almadén. Así, la superintendencia de las Minas se enfrentaba a problemas idénticos a los que los industriales británicos comenzaban a superar mediante la generalización de lo que Gaudemar denomina «disciplina panóptica" ${ }^{15}$. Mientras tanto, el Plan..., perfecto exponente de ese "pensamiento antiguo», preindustrial, permanece ajeno a esa forma de disciplina laica, proponiendo a la religión como método principal para restaurar entre los trabaja. dores ese necesario "espíritu de subordinación y obediencia».

El recurso a la disciplina religiosa revela la incapacidad de las autoridades mineras para controlar de manera eficaz la fuerza de trabajo. Una gestión del trabajo más favorable a los intereses reales tropezaba con dos obstáculos difícilmente superables: la «economía moral» del «mineraje» y la debilidad de los resortes técnico-económicos encargados de maximizar la productividad del trabajo. De ahí la coherencia del proyecto de Ortuño. Si el segundo obstáculo, dada su dependencia del nivel de desarrollo tecnológico y económico general de la sociedad española, carecía de soluciones, el primero, por el contrario, parecía abordable. Modificando la «economía moral», la interiorización de los valores religiosos produciría a un tiempo súbditos modélicos.y no menos modélicos trabajadores.

14 Marglin (1977), p. 85.

is Gaudemar (1981a), p. 258. Modelo correspondiente a la primera etapa del desarrollo capitalista, fundado sobre la extracción de plusvalía absoluta. Descrito como *modelo de vigilancia directamente coercitiva». 
Veamos con algún detalle lo que sucedía en Almadén. A comienzos del siglo xix, las Minas atravesaban una delicada situación. Diversos problemas, como eran el atraso tecnológico, la carencia de técnicos y directivos especializados, el mantenimiento de una estructura organizativa rígida, la carencia de principios de actuación y el constante enfrentamiento entre la dirección «política» - la Superintendencia - y la dirección «facultativa» - la Dirección-, entorpecían el desenvolvimiento de las actividades productivas. Pero eran otros dos problemas los que revestían una especial gravedad: uno, externo, originado por las dificultades hacendísticas de la Monarquía, era la insuficiencia presupuestaria; otro, interno, la gestión de la fuerza de trabajo. Por razones obvias, nos centraremos en el segundo de ellos.

Este tema, importante en cualquier proceso de producción, adquiría una relevancia especial en las Minas, debida, por un lado, a la elevada cifra de mineros integrantes del censo laboral y, por otro, a la intensidad en trabajo de todas las tareas ${ }^{16}$. No obstante, hasta 1760 , las Minas habían tropezado con serias dificultades para reclutar trabajadores en cantidad suficiente para alcanzar los volúmenes de producción de azogue necesarios para satisfacer la demanda de la minería argentífera americana. Por el contrario, durante la segunda mitad del siglo xvili, una oferta sostenida y creciente de trabajo fue conseguida mediante la interacción de elementos diversos: existencia de una población proletarizada, tanto en la localidad como en una extensa área geográfica circundante, fenómeno al que no son en absoluto ajenas las estructuras agrarias regionales (propiedad de la tierra, tipos de cultivo, etc.) y la reducida dimensión de la producción artesanal; el crecimiento demográfico; la movilidad espacial de la fuerza de trabajo; la complementariedad temporal de las actividades agrícolas y mineras ${ }^{17}$; la política poblacionista adoptada por las autoridades; la creación de un mercado interno de trabajo. Gracias a este aumento de la oferta de trabajo fue posible imprimir a la producción de mercurio un ritmo expansivo nunca antes conocido ${ }^{18}$.

16 Durante el periodo comprendido entre 1794 y 1811, las «Nóminas» (costes salariales) representaban en torno al 70 por 100 de los costes de explotación. Véase Dobado, op. cit., p. 388.

17 Normalmente, las campañas mineras se llevaban a cabo durante los meses comprendidos entre el comienzo del otoño y el final de la primavera. Con la llegada del verano se suspendian las fundiciones y la extracción del mineral, reduciéndose los trabajos interiores a la conservación de las minas (fortificación y desagüe). Así, buena parte de los mineros podian ocuparse durante la temporada estival en las faenas agrícolas mejor retribuidas (cosecha de granos y vendimia), con lo que no sólo complementaban los ingresos obtenidos en las Minas, sino que también se «saneaban», combatían las secuelas dejadas en su «economía orgánica» por las insalubres labores mineras. Esta complementariedad entre actividades mineras y agrícolas fue de vital importancia para las Minas en lo que se refiere a la captación de trabajadores, a la reproducción de la fuerza de trabajo y al mantenimiento de un bajo nivel salarial.

is Antes de 1759, las medias decenales de producción anual de azogue nunca superan los 7.580 quintales conseguidos en la década 1740-1749. Por el contrario, en 1760- 
Pero la mera presencia en Almadén de un número adecuado de trabajadores, motivada por la ausencia de opciones alternativas a las Minas para la obtención de los medios de subsistencia, no bastaba. Habida cuenta de que implicaba un coste económico, que adoptaba la forma de salarios y jornales, se trataba de maximizar su rentabilidad a través de la regulación del proceso de trabajo, de optimizar la productividad en base a una codificación de las relaciones laborales.

Es aquí donde aparece el conflicto, ese aspecto cualitativo desconocido en la gestión de los restantes factores de producción. Para hacer productiva la adquisición en el mercado de la fuerza de trabajo, sus portadores, los hombres, tienen que aceptar la coacción implícita en todo proceso de trabajo. Compulsión que, pese a poder no ser sentida como tal, se hallaba presente desde el momento en que los mineros traspasaban la puerta de los "cercos" interiores, iniciándose en el acto del «asiento», mediante el cual se procedía a la distribución entre las diferentes tareas y zonas de las minas de los trabajadores asistentes a cada una de las cuatro entradas diarias, y concluvendo con el registro al que los «porteros" sometían a los trabajadores a su salida con el fin de impedir el robo de pólvora, barrenas y otros utensilios, pasando por la prohibición de abandonar las minas entre horas señaladas a tal efecto a toda persona que no dispusiera de la oportuna "papeleta». Con el paso del tiempo fue ganando en complejidad, aunque no siempre en eficacia, el conjunto de disposiciones que regulaban la conducta del trabajador en el interior de las minas, abarcando desde su actitud ante los superiores hasta su desplazamiento por los pozos y galerías, pasando por los procedimientos empleados para aplicar el trabajo sobre los criaderos de mineral. Ante la ausencia de máquinas que impusiesen una regulación mecánica del trabajo, la codificación del comportamiento al servicio del orden productivo reposaba en la vigilancia del personal supervisor («oficiales de mina», «ayudantes de oficial», «sentadores», «porteros» $y$ «sobreestantes»). Las infracciones por ellos denunciadas se traducían en sanciones de diversa rigurosidad (multas, jornadas no retribuidas, suspensiones temporales o definitivas, reclusiones en locales de las Minas o en la cárcel municipal y entrega a las autoridades judiciales).

Pero la mera represión es insuficiente e implica costes económicos. En primer lugar, las minas, lejos de constituir el universo transparente al control representado por el panóptico de Bentham ${ }^{19}$, eran, por su propia configuración

1769 , dicha media se elevó a 11.637 quintales. llegando a ser de 20.040 quintales en 1800-1809. Véase Dobado, op. cit., p. 385.

19 Figura arquitectónica así descrita: "Conocido es su principio: en la periferia, una construcción en forma de anillo; en el centro, una torre, ésta, con anchas ventanas que se abren en la cara interior del anillo. La construcción periférica está dividida en celdas, cada una de las cuales atraviesa toda la anchura de la construcción. Tienen dos ventanas, una que da al interior, y la otra, que da al exterior, permite que la luz atraviese la celda 
espacial y por el sistema de laboreo empleado hasta comienzos del siglo xIX, profusas en obscuridades, recovecos y demás áreas de difícil supervisión. En segundo lugar, la fragmentación espacial y funcional del proceso de trabajo interponía trabas adicionales a una inspección eficaz. En tercer lugar, el número de los miembros del personal de control era reducido en relación con la magnitud de su actividad específica. Además, con cierta frecuencia, éstos incumplían voluntariamente sus funciones o, solidarios con sus antiguos iguales, permitían algunas prácticas fraudulentas (cobro de jornales no devengados, «sentar» para una tarea más trabajadores de los necesarios, no supervisar la calidad del trabajo o, simplemente, no asistir a sus «entradas» obligatorias), dando la impresión de originar una especie de contrapoder de la base, a veces enfrentado al poder de las autoridades. Así, en numerosas ocasiones, el personal supervisor es duramente recriminado por su "falta de celo», llegándose a las amenazas de revocación de sus puestos. En cuarto lugar, el mantenimiento de la disciplina se enfrentaba, en última instancia, con unos seres dotados de una «economía moral» que podía poner en cuestión el modelo de gestión de la fuerza de trabajo instrumentado mediante el régimen disciplinario.

Además de actuar «dentro del orden», motivados por la coerción económica que les obligaba a acudir a las minas, alentados por los estímulos monetarios de los mecanismos retributivos y sensibles a las penas impuestas por el sistema represivo, los mineros también se salían de estos cauces, cuestionando individual y colectivamente los criterios de jerarquía y productividad imperantes. Así aparecía cotidianamente una aceptación parcial de la coacción intrínseca al proceso de trabajo, compatible con la adopción de prácticas tendentes a sabotear el orden de la producción. La respuesta de los trabajadores a las durísimas condiciones laborales consistía más en una heterogénea resistencia pacífica (absentismo, baja calidad del trabajo, escasa productividad, robos de útiles y materiales, fraudes de diversa índole, etc.) que en un enfrentamiento manifiesto con la dirección - del cual también existen abundantes ejemplosAhora bien, esta particular forma de comportamiento entorpecía, ciertamente, el desarrollo de las actividades productivas.

Vistos los problemas, pasemos a las soluciones concretas. Tras la «Introducción» y el «Discurso previo», Ortuño pasa a exponer el conjunto de proposiciones que constituyen el Plan... en sentido estricto. En contraste con la tónica general de las dos primeras partes del texto, abandona las declaraciones de principios o los planteamientos abstractos, ciñéndose a mencionar las disposiciones concretas que conforman su proyecto de reforma. El Plan... queda

de una parte a otra. Basta entonces situar un vigilante en la torre central y encerrar en cada celda a un loco, un enfermo, un condenado, un obrero o un escolar. Por el efecto de la contraluz, se pueden percibir desde la torre, recortándose perfectamente sobre la luz, las pequeñas siluetas cautivas en las celdas de la periferia.» Foucault (1981), p. 203. 
reducido a la enumeración de unas medidas que no van más allá de una mera reorganización administrativa y económica de los servicios religiosos en $\mathrm{Al}$ madén ${ }^{20}$.

Un texto que, repleto en sus partes iniciales de proposiciones normativas y positivas respecto a una pluralidad de temas fundamentales (ordenamiento jurídico-político de la sociedad, papel de la religión y los eclesiásticos, colaboración Iglesia-Estado en el mantenimiento del orden social y del orden productivo, naturaleza humana, comportamiento de la población de Almadén), de olvidos no menos significativos que las menciones expresas (condiciones materiales de vida de los habitantes, posibilidades de modificación de las mismas), destinados tanto éstos como aquéllos a la defensa del régimen absolutista y del orden productivo, aparece desde un principio como claro ejemplo de producción ideológica, acaba convirtiéndose en un proyecto que podría haber salido de la pluma de un burócrata eficiente. Perdida la amplitud de miras del pensador, sólo permanece la capacidad organizativa del funcionario eclesiástico. Las medidas previstas en el Plan... decepcionan.

La reforma de Ortuño, probablemente, permitiría una más sistemática emisión de auténtico mensaje incorporado por el discurso religioso:

Hijos míos; la potestad de vuestro Príncipe viene de Dios, de quien dimana todo poder: Vosotros debeis obedecerle no sólo por temor, si no más bien por obligación y amor: estad sumisos al Rey, $y$ a sus ministros como enviados suyos, para proteger el bien, y castigar el mal: dad al César, lo que es del César, y a Dios lo que es de Dios, pues éste es el orden de la Providencia ${ }^{21}$.

Pero está destinado a fracasar en lo que a su objetivo disciplinario se refiere, porque, en definitiva, propone unas medidas más adecuadas para «restablecer el culto exterior a que es tan acreedor la majestad de nuestro Diosm que para contribuir a la formación de los trabajadores idóneos para el mante-

${ }^{20}$ Dichas medidas son: 1) Sustitución definitiva de los «caballeros frailes* de la Orden de Calatrava por el clero secular dependiente del arzobispo de Toledo al frente de la asistencia religiosa. 2) Creación de una nueva parroquia en Almadén (con lo que serían dos las existentes), quedando en ellas integrados los curatos cuya desaparición se propone, así como los asentamientos de San Benito y Alamillo, y de otra más en Almadenejos, donde hasta entonces no había ninguna. Descripción de las dotaciones económicas del personal eclesiástico y de las fábricas. 3) Regulación precisa de las obligaciones sacerdotales, capellanías, memorias pias y cofradías. 4) Exención del pago de derechos parroquiales en aquellas ceremonias que no revisten características especiales, habida cuenta de la general condición de trabajadores o empleados de las Minas del vecindario de Almadén y Almadenejos. 5) Supresión de la Botica del Real Hospital e instalación de «dos o más boticas de particulares», con el fin de que los habitantes «se retraigan del Real Hospital, y que éste y la Real Hacienda tengan un ahorro muy considerable».

${ }^{21}$ Ortuño, op. cil., p. 12. 
nimiento incontestado del orden productivo. La asunción de valores disciplinarios, tales como el respeto a la propiedad, la preferencia por la ética del trabajo, la sumisión a la autoridad o el rechazo a las relaciones interpersonales no sancionadas sacramentalmente, exigía una reforma mucho más profunda que la propuesta por Ortuño. Modificación de los fines y medios del discurso religioso que excedería de los cauces permitidos por la jerarquía eclesiástica y que entrañaría un enfrentamiento inevitable con el papel desempeñado por la Iglesia en el Antiguo Régimen. Además de propugnar pautas de conducta distintas, si no contrarias, a la experiencia cotidiana de los habitantes de Almadén, Ortuño se encuentra con la dificultad adicional consistente en conciliar la defensa global del orden político e ideológico absolutista con la difusión de valores favorables al orden productivo industrial, cuales eran los necesitados por un establecimiento de las dimensiones y de la complejidad de las Minas:

Respetad sus intereses [del rey], y sabed, que la cosa más leve que extraigais de sus almacenes, y hasta el tiempo que dejais de trabajar, como debeis, para devengar el jornal, que se os da, es un verdadero robo y una injusta usurpación; sed fieles en el desempeño de vuestros respectivos destinos ${ }^{22}$.

Una población como la de Almadén, casi por completo proletarizada, vi. viendo entre la miseria y la enfermedad, con unas pautas de consumo adesor. denadas", abierta al exterior, amiga de imitar el comportamiento de las clases dominantes, formadas en buena medida por forasteros de paso, viviendo de espaldas al mundo rural, familiarizada con el riesgo y el sufrimiento propio y ajeno, presumiblemente marcada por una consideración acerca de la fugacidad de la existencia humana y por una preferencia por lo inmediato frente a lo futuro, difícilmente podía hacer suyos los valores que conforman la trascendente tríada reaccionaria (propiedad, familia y religión) defendida por Ortuño.

\section{El olvido de Ortuño}

Ortuño constituye un caso aislado entre quienes, desde muy diterentes posiciones y con fines diversos, se ocuparon por escrito de las Minas de Almadén durante los siglos xvirI y xIX. Todos los autores manifestaron en alguna medida la impresión causada en su sensibilidad por las lamentables condiciones que presidían la existencia de los mineros. En Ortuño, cualquier mención al respecto brilla por su ausencia, permaneciendo insensible frente a un

\footnotetext{
22 Ibidem.
} 
aspecto de la realidad no menos llamativo que el pretendido escaso respeto de los mineros a los principios de autoridad, propiedad y relación entre las personas de uno y otro sexo, caros al autor. Nuestro sacerdote, preocupado por la indiferencia religiosa, el adulterio, el amancebamiento y el menoscabo de la Real Hacienda, se muestra desinteresado por el desarraigo de la numerosa población emigrante, la elevadísima incidencia de los accidentes y enfermedades profesionales; por el extendido trabajo infantil o por el reducido poder adquisitivo de los salarios. Ajeno a la auténtica experiencia cotidiana de los habitantes de Almadén, Ortuño manifiesta su desvelo por la existencia ultraterrena en un pasaje en el que, por primera y última vez, de manera muy breve, menciona lo que tanto asombró a sus contemporáneos:

.. unos vasallos que sacrifican, su salud, vidas, e intereses en obsequio de su Señor, y Soberano, no deben carecer de los medios indispensables para conseguir su bien espiritual, y la salvación de las almas ${ }^{23}$.

Como puede apreciarse, la mención a los sufrimientos de los mineros apa rece antes como justificación de la necesidad de atender a la «vida eterna» de los mismos, destinada a la postre a reforzar la presencia terrenal de la Iglesia, que como valoración de una dolorosa realidad.

Insistiré sobre este olvido de los costes sociales por parte de Ortuño. Sin negar la posible incidencia de ot:as explicaciones, una serie de razones inducen a considerar la ausencia de referencias acerca de este tema como un silencio intencionado, debido fundamentalmente a su voluntaria decisión de convertirse en defensor de los intereses dominantes. En primer lugar, puede argumentarse que otros autores sí consideraron extraordinarias las condiciones imperantes en Almadén. Algunos textos no coincidentes en el tiempo ponen de manifiesto el carácter excepcional que revestía la existencia de los mineros frente a otros colectivos de trabajadores, que se manifestaba en el nivel salarial, en la dureza e intensidad del trabajo, en la peligrosidad del mismo y en la incidencia de las enfermedades profesionales. Veamos algunos ejemplos:

1) Gozan estos trabajadores de diferentes salarios o jornales según sus respectivas tareas...: Pero el que más dotado está es el destajero, que se ocupa en hacer barrenos para arrancar la piedra mineral; y éste en el discurso de seis horas, que es su tarea, gana seis reales de vellón, advirtiendo que esto es sólo los días de trabajo; de manera, que descontando los días de fiesta y temporada, que se suspenden los barrenos a fin de que la mina se refres-

\footnotetext{
"Ibidem. p. 14.
} 
que algo de los fuegos de la pólvora, viene a salir a fin de año con tres reales al día. Con esto es una compasión ver la pobreza de este mineraje, pues es indubitable, que pueblo ninguno de la provincia de la Mancha tenga el alcance, que éste de Almadén ${ }^{24}$.

2) ... además que para esta especie de trabajos tan penosos no se pueden atraer los hombres sino por el aliciente del premio, el que siendo miserable y corto en proporción de la dotación causa la desaparición de gran parte de ellos al entrar la primavera $\sin$ que esperen los que restan en ellas otra recompensa que quedar imposibilitados a los 25 ó 30 años de trabajo por efecto o toque del pecho de subir y bajar cerca de 700 peldaños de incómodas y peligrosas escaleras de mano, y por azogados temblones, y en fin, sin esperar más que indigencia y miseria en que pasan el resto de sus días, si antes no fenecen en la caída de tales escaleras, o a la violencia de la cigüeña de un torno que los parte o de un peñote que los aplasta ${ }^{25}$.

3) ... la clase de servicio de los que se invierten en ellas, el cual es más penoso aún que el militar, pues en éste, no siendo en campaña, desempeña el soldado algunas veces obligaciones molestas, pero no perjudican a su salud ni ofrecen un riesgo continuado, cuando el minero de Almadén introduciéndose diariamente a más de 300 varas de la superficie, respira todo el tiempo que está en aquellos sitios cavernosos, miasmas mercuriales y otros sumamente perjudiciales, al paso que se ocupa en un trabajo corporal duro y penoso, viéndose amenazado de los riesgos y acontecimientos desgraciados que tan frecuentes son en aquellas minas, los cuales por otra parte acortan insensiblemente los días de los que trabajan en ellas, siendo por consecuencia necesario adoptar las medidas que puedan contribuir a disminuir el perjuicio que experimentan en su salud... ${ }^{26}$.

A estas citas podrían añadirse un sinfín de ellas relativas a las contaminación ambiental causada por la fundición del cinabrio en los hornos, la temprana incorporación de la población infantil al trabajo ${ }^{27}$, el hacinamiento en unas

${ }^{24}$ Parés y Franqués (1778), p. 39.

${ }^{25}$ Morete de Varela (1857), p. 382. Texto redactado en 1804.

26 Cabanillas (1838), pp. 440 y 441.

${ }^{27}$ Las primeras disposiciones formales restringiendo la contratación infantil datan de agosto de 1835. En 1837, la edad mínima exigida para entrar en las minas quedó establecida en diecisiete años. Sin embargo, en 1882, el médico Gómez de Figueroa aconsejaba la prohibición de admitir menores de dieciséis años, lo que da a entender que éstos no se encontraban excluidos de los trabajos, al menos exteriores. 
viviendas insuficientes para alojar a los residentes habituales y a los emigrantes de temporada, la carestía de las subsistencias ante la insuficiente producción agraria en Almadén y las dificultades de transporte - derivadas de la deficiente red viaria y del emplazamiento de la localidad - y la reducida capacidad del Hospital de Mineros para atender a una población numerosa afectada por un elevado índice de morbilidad. En fin, un cuadro de problemas similar al que los estudios de historia social y económica han detectado como coste inevitable de la industrialización, pero que en Almadén adopta aspectos particulares como son su independencia respecto a cualquier proceso de desarrollo capitalista de ámbito regional o nacional y un rápido deterioro de la «economía orgánica» de los trabajadores difícilmente repetible. Este último aspecto es el que me interesa subrayar. Todavía cincuenta años después de la aparición del opúsculo de Ortuño se escribía sobre el trabajo de los mineros en los siguientes términos:

Ningún ejercicio del campo, ninguna faena de las industrias ordinarias exige la aptitud física y condiciones individuales que las minas de Almadén, no tanto por su profundidad, cuanto por su naturaleza. El hombre más sano y vigoroso para aquéllas, pierde de seguro su lozanía y su vigor a los dos años de ejercitarse en las minas de Almadén, antes puede decirse de familiarizarse con las más sencillas maniobras de su explotación. Las constituciones, pues, fuertes y atléticas, no muy tarde vienen a convertirse en débiles, delicadas y dispuestas fácilmente a toda clase de enfermedades.

Regístrense los libros de defunciones de su respectiva parroquia, compárese con los correspondientes a otras poblaciones, y se echará de ver que sus habitantes, sin otra causa que la de dedicarse a las minas de azogue, viven, por término medio, una tercera o cuarta parte menos que los de pueblos diferentes ${ }^{28}$.

Prescindiendo de antemano del intento de exponer siquiera una parte reducida de la información existente para el período 1760-1885, parece razonable considerar los ejemplos mostrados como prueba suficiente de que ciertos aspectos negativos de la realidad de Almadén, olvidados por Ortuño a pesar de su importancia en la configuración de las condiciones materiales de vida de sus habitantes, revestían características excepcionales para cualificados autores españoles de la época. Así, queda descartada la hipótesis de que Ortuño no encontrara en Almadén diferencias dignas de mención con respecto a otras localidades en lo que a la suerte de sus moradores se refiere.

${ }^{23}$ Sánchez-Aparicio (1858), p. 754. 
En segundo lugar, datos más impersonales que los anteriores, como son los obtenidos de la documentación administrativo-contable elaborada en el transcurso del tiempo por las propias Minas, confirman los juicios individuales. En el año en que escribe Ortuño, 1804, culmina una etapa de drástico empeoramiento del poder adquisitivo de los salarios que condujo a los habitantes de Almadén a una situación de extrema miseria. Varios indicadores dan cuenta de un fenómeno que difícilmente pudo pasar inadvertido para cualquier observador bienintencionado.

En Almadén, las carestías se traducían de manera casi instantánea en despoblación. Esto es, las dificultades de abastecimiento, siempre acompañadas de elevaciones del precio del grano, tenían como efecto inmediato reducir el número de habitantes. Prescindiendo del incremento de la mortalidad catastrófica, ello era debido al abandono de la localidad por parte de miembros de los sectores menos integrados (emigrantes de temporada y vecinos de reciente instalación) con el fin de encontrar lugares, los de procedencia y otros, con un menos difícil acceso a una dieta mínima. Obviamente, la intensidad de esta especie de huida en busca de alimentos más asequibles dependía de la magnitud del incremento del precio del trigo. Pues bien, en 1804, el «pan bazo», de 2 libras de peso, artículo de consumo básico, alcanzó el precio máximo hasta entonces conocido, siendo su valor medio en dicho año de 2,1 reales. En imparable elevación durante el transcurso del año, la unidad citada, que en enero se pagaba a 1,4 reales, llegó a costar 3,3 reales durante el período septiembre-diciembre. Si tenemos en cuenta que, según un informe de la contaduría de las Minas, el consumo familiar medio de pan entre los mineros era de 2,6 «panes" y que los trabajadores mejor remunerados, los entibadores, obtenían unos ingresos mensuales de 210 reales, podremos hacernos una idea de los extremos de depauperación que conocieron las familias de los mineros que percibían jornales de 5 y 4 reales, los más comunes. En esta tesitura, ni los ingresos complementarios aportados por otros miembros de la familia ni las alternativas al mercado en la consecución de alimentos servirían para garantizar la subsistencia de las unidades familiares. El delicado equilibrio de los años «normales» se vio profundamente alterado. Además, dicho año vino precedido de otro especialmente adverso, 1803, y de un período dilatado de altos precios que, con breves intervalos en los que se atemperó el coste de la subsistencia, arranca en torno a 1785 . Resumiendo, en el año de redacción del Plan... el largo proceso de detericro de los salarios de los mineros alcanza su cota máxima, resultado de la confrontación entre unos salarios nominales relativamente rígidos al alza y unos precios de productos agrícolas (trigo, carne, aceite y garbanzos) en crecimiento sostenido.

Confirmando el empeoramiento registrado por las posibilidades de consumo de los trabajadores de Almadén desde finales del siglo xviII, deducido a 
partir del análisis de precios y salarios, los datos relativos a la natalidad y al movimiento migratorio corroboran la despoblación parcial de Almadén originada por las crisis de subsistencia. En efecto, si la media anual de nacimientos entre 1790 y 1801 se sitúa en 225 , en el sexenio 1802-1807 desciende a 188. Por otra parte, mientras que en la década 1791-1800 las solicitudes medias anuales de empleo en las Minas fueron 1.159, en los seis años transcurridos desde 1801 a 1806 dicha cifra se redujo a 291. Pero, además, la participación de los nacidos en Almadén frente a los forasteros en el total de solicitantes se elevó de manera considerable en el segundo período mencionado.

Por otra parte, datos procedentes del Hospital de Mineros informan del incremento de sus actividades asistenciales en torno a 1804. En efecto, frente a las 16.500 estancias diarias de enfermos en 1803, fueron 21.000 las correspondientes a 1804 y 25.700 a 1805 ; posteriormente, en 1806 y 1807, dicha cifra se redujo a 16.000 y 10.000 , respectivamente. Dado que la población se resistía a ser ingresada en el Hospital, prefiriendo los enfermos permanecer en sus domicilios, y que los mineros afectados por enfermedades profesionales no solían recibir asistencia hospitalaria, los datos ofrecidos dan tan sólo una idea aproximada del acusado empeoramiento del estado sanitario de la población en 1804 y 1805 .

Así, durante los años contemplados disminuvó apreciablemente el atractivo ejercido hasta entonces por Almadén como lugar de residencia para hipotéticos pobladores, más o menos estables, que decidieron emplearse en las Minas. Este hecho tuvo, al menos, una consecuencia negativa para la población que permaneció en la localidad: la mayor incidencia de los accidentes y enfermedades profesionales. Observando las cifras de extracción de cinabrio y de producción de azogue, se aprecia que las Minas mantuvieron durante esos años un elevado nivel de actividad ${ }^{29}$. Al mismo tiempo, asistimos a la reducción del censo minero. Por tanto, se infiere que la consecución de voluminosas «sacas» de azogue fue posible gracias al aumento de la participación en el proceso productivo de los trabajadores disponibles. Estas coyunturas, repetidas en otras ocasiones durante la primera mitad del siglo xIx, se traducían siempre en un deterioro de la «economía física» del «mineraje». O, lo que es lo mismo, en un empeoramiento de las condiciones materiales de vida de los mineros, ya que, trabajando jornadas mavores que las habituales (seis horas) ${ }^{30}$

20 Excepto en el año minero 1801-1802, en el cual, por razones desconocidas, no hubo fundición de cinabrio, pero sí extracción de mineral, aunque inferior a la media de ese periodo.

Durante largo tiempo, especialmente a partir de 1830, se debatió intensamente acerca de la conveniencia de prohibir la prestación de mentradas dobles» (doce horas). Esta discusión, en la que junto a consideraciones de índole estrictamente humanitaria se detecta la preocupación por los costes laborales derivados de la peculiar asistencia social a los mineros *estropeados» ejercida por las Minas y por la reproducción a largo plazo de la oferta de trabajo, no se materializó en ninguna interdicción de carácter general, pues 
y/o más intensamente, veían aumentar el ya de por sí elevado riesgo de resultar afectados por los accidentes y enfermedades profesionales.

Ahora bien, dejando a un lado los aspectos relativos a la «economía orgánica" de los mineros, la ausencia de menciones en el Plan... de la dramática situación vivida por los habitantes en torno a 1804 podría ser, en cierta medida, disculpable habida cuenta del carácter general que revistió la crisis de esos años. Así, desde una cierta óptica, lo sucedido en Almadén sería simplemente un ejemplo más dentro de un contexto global no menos afectado por las consecuencias de la escasez y de la carestía de las subsistencias. Sin embargo, no por ello la falta de referencias deja de ser significativa para comprender la visión del mundo de Ortuño.

En tercer lugar, calificar de olvido intencional la inexistencia de comentarios descriptivos de las condiciones materiales de vida de los mineros encuentra un nuevo argumento al comprobar que otros autores, cuya defensa del orden productivo resulta incluso más explícita que la de Ortuño, nunca dejaron de subrayar alguno de los costes sociales surgidos en la producción del azogue. Así, Ortuño constituye un caso excepcional, mostrándose incapaz de ofrecer una justificación del orden social - concepto amplio que incluye como elemento fundamental el orden productivo- distinta de la obediencia y de la lealtad naturalmente debidas por los súbditos al monarca en virtud de la procedencia divina de su mandato. Preso de la lógica de su discurso ideológico, Ortuño sólo puede proponer como instrumento para la consecución del fin deseado la unidad represión/persuasión, correspondiendo el ejercicio de la primera al poder civil (polítice y económico) y el de la segunda, considerado más eficaz que el primero, a la Iglesia.

\section{El "Catastrophe...» de Parés y Franqués}

Su autor, quien, tras su paso por Almadén, acabaría llegando a ser el médico de la familia real, nada tiene de revolucionario. Sin embargo, su versión de la realidad social surgida en torno al funcionamiento de las Minas es radicalmente distinta a la ofrecida por Ortuño. Los temas que a éste se le quedaron en el tintero fueron expuestos con todo lujo de detalles por aquél treinta años antes.

Así, respecto a las motivaciones laborales del «mineraje» escribe:

en algunos períodos de oferta de trabajo insuficiente se llegó a obligar a los trabajadores del exterior a realizar «entradas extraordinarias» tras la finalización de su jornada normal. Por otra parte, en 1882 todavía resultaba frecuente la kentrada» de duración doble. 
Quien leyese esta miserable carrera de nuestros Mineros juzgara, que se entregan a ella estos infelizes llevados de algún superior estipendio para tan peligrosas, y melancólicas tareas. Pero, $[\ldots]$ es bien al contrario; pues nada más les mueve a abandonar su salud, y vida, que su misma miseria y' necesidad: miseria, porque los forasteros [...] lo hacen por no tener en sus pueblos con qué pasar su vida, y juzgan conveniencia mayor pasarla con desdicha, que acabar con hambre: y necesidad, porque los naturales, como desde niños no aprendieron otro que este ejercicio, forzosamente deben sufrir el pesado yugo de él, pues se hallan adultos, e incapaces de otro oficio ${ }^{31}$.

En cuanto a los accidentes y enfermedades profesionales, su descripción no es menos detenida:

1) Cuantas desdichas padecen estos operarios en este primero paso de entradas a nuestras Minas. Unas veces se rompe la maroma, otras se dispara el huso, y otras la misma escalera se desclavó; y se ven, los que andan tan peligroso camino, llegar rodando a lo más profundo con heridas de mucha gravedad, y contusiones mortales, si no llegan muertos ya... ${ }^{32}$.

2) ... formados los barrenos para arrancar la piedra mineral $[\ldots]$ se dispara muchas veces intempestivamente antes de poderse retirar el minero a sitio seguro; cuando los peñones en que revienta el astial, y la misma pólvora encendida, dejan manco a uno, entuertan a otro, a otro le quemaron los ojos, y cara, y a infinitos dejaron cadáveres en el mismo sitio ${ }^{33}$.

3) Las eficiencias de los minerales no son tan ejecutivas como las desgracias referidas, aunque son más funestas; pues van paulatinamente destruyendo a los mineros con accidentes más, o menos crónicos, según su casta y disposición de los sujetos ${ }^{34}$.

Ninguno de los factores que influían significativamente sobre las condiciones materiales de vida de la población (salarios, trabajo infantil, contaminación ambiental, política poblacionista, enfermedades, hábitos de consumo, etc.) escapan al expresivo comentario de Ortuño. Por tanto, las diferencias de talante y objetivos con el Plan... son obvias. No menos evidentes son las di-

${ }^{31}$ Parés y Franqués, op. cit., p. 38.

${ }^{32}$ Ibidem, pp. 12 y 13.

${ }^{33}$ Ibidem, p. 13.

${ }^{34}$ Ibidem, p. 14. 
vergencias entre el período reformista en que Parés y Franqués redacta su obra - dedicada al Rev- y la época de reacción absolutista que enmarca la oposición del opúsculo de Ortuño. Más interés tiene poner de manifiesto ese elemento común que permite considerar a ambos como exponentes de un mismo "pensamiento antiguo".

Dicho elemento compartido consiste en la actitud ante el proceso productivo. En primer lugar, éste nunca es cuestionado. Ni por un momento, Ortuño o Parés y Franqués llegan a poner en duda la conveniencia de proseguir la producción de mercurio. Si, en el caso del Plan..., esta certidumbre en la necesidad de mantener el funcionamiento de las Minas resulta plenamente coherente, no sucede lo mismo con el Catustrophe.... en el que la constante exposición de los costes sociales viene acompañada de una valoración global positiva de los resultados del proceso productivo. Cegado por los beneficios económicos obtenidos con la venta de azogue y por la abnegación de los mineros, Parés y Franqués se olvida de unas consecuencias sociales negativas a las que, por otra parte, tanto espacio dedica.

En segundo lugar, tanto para Ortuño como para Parés y Franqués, el proceso productivo permanece como un marco inmutable, predeterminado por una Naturaleza que impedía la obtención del mercurio sin sufrimientos, y frente al cual al hombre sólo le cabe la aceptación resignada de sus consecuencias o, todo lo más, una suavización a posteriori de las mismas. Reflejo de una sociedad carente de medios eficaces para dominar la Naturaleza, esta concepción de la posición del hombre sobre la Tierra, tan distinta de la que poco después veremos encarnada en los ingenieros de minas, no debe sorprendernos. Así, para Ortuño, el trabajo en las Minas representaba la cuota de sacrificio con que unos determinados súbditos debían contribuir al inexcusable "real servicio». Dado que el sacrificio no acaba de ser aceptado en su totalidad por los mineros, la religión infundiría en las conciencias el estoicismo necesario para lograr el orden productivo que permitiría la reproducción anual de las sacas de azogue. Parés y Franqués no puede superar el sentimiento de indefensión ante la realidad de un proceso productivo que se presenta como un dato inamovible, cuya modificación se escapaba casi por completo a la voluntad de los hombres. De ahí que sus sentimientos humanitarios no alcancen a producir transformaciones en el proceso de trabajo y tengan por fuerza que circunscribirse a mitigar sus consecuencias. Por ello, aboga por una aminoración de esas secuelas gracias a la paternal y solícita intervención del monarca en forma de incremento de los fondos destinados a asistir a los mineros heridos o enfermos y a las viudas y huérfanos de los fallecidos a causa del «real servicio». Por esta vía se llega a su particular utopía laboral, en la que los mineros trabajan con abnegación y el Rey les asiste benéficamente.

Nos hallamos, pues, en presencia de dos corrientes, una compasiva y otra 
disciplinaria, de un mismo pensamiento, que tiene por principal nota distintiva la forzada aceptación de las condiciones técnico-económicas del proceso productive

\section{V. «El pensamiento moderno»}

A mediados del siglo xIx, este tipo de planteamientos desaparece del nuevo pensamiento representativo de la época. El discurso «moderno» llevaba a cabo una defensa del orden productivo que no necesita el abandono de la esfera técnico-económica. Para estos autores, se trataba de entender el ámbito de actuación de dos de las más poderosas fuerzas motrices del siglo: el mercado y el progreso tecnológico. Junto a la maquinaria moderna y la libertad económica se instaurarían unas condiciones de trabajo menos adversas para los mineros y se reducirian las necesidades de vigilancia del proceso de trabajo. Así se llegaba a la conciliación entre necesidad —adecuación del proceso productivo a los requerimientos y posibilidades del momento- y deseo -disminución de unos costes sociales no estrictamente inevitables-. En buena medida, nos encontramos en las obras de Sánchez-Molero, Bernáldez y Rúa con una temprana versión del mito social del capitalismo: el advenimiento del imperio de la felicidad de la mano del binomio crecimiento económico/avance técnico-científico.

La finalidad última del "pensamiento moderno" era propiciar una transformación en profundidad del esquema tradicional de funcionamiento de las Minas. Propósito que constituye una abierta ruptura con el «pensamiento antiguo", que nunca pudo ni siquiera imaginar esta posibilidad. Es ésta la nota básica que permite considerar la existencia de dos actitudes intelectuales bien diferenciadas entre los ensavistas que se ocuparon de los aspectos sociales del proceso productivo.

Bernáldez y Rúa exponen claramente la causa que motivó la redacción de su memoria:

Cesaron ya, para no reproducirse en la historia de la industria, aquellos tiempos en que las Minas de Almadén especialmente y algún tanto las de Idria y Huancavelica, surtían con un monopolio arrogante los mercados de América [...] parece eclipsar. el futuro brillo y la gloria secular de nuestra antigua y codiciada joya de Almadén; joya amenazada de un demérito considerable $e$ inminente, si no se refunde en el crisol de los adelantos moderıos 
y no se reconstruye a la sombra de las verdaderas prescripciones económico-industriales ${ }^{35}$.

En definitiva, se trataba de recuperar para el mercurio español la cuota del mercado internacional perdida a favor del azogue californiano. A partir de 1849 , la puesta en actividad de las minas de cinabrio de Nuevo Almadén, situadas en el valle de San José, en la Alta California, supuso un incremento notable de la producción mundial, que saturó el mercado, redujo los precios y contrajo las exportaciones españolas de azogue, en especial a América, principal cliente hasta entonces.

En sintesis, el proyecto de los ingenieros consistía en disminuir los costes de explotación a fin de incrementar la competitividad exterior. Para ello sería necesaria una reorganización total del progreso productivo apoyada en los «adelantos modernos» $y$ en las «verdaderas prescripciones económico-industriales». Esto es, maquinismo y economía política, dos destacados elementos legitimadores del nuevo papel de la burguesía en la sociedad e impulsores de la industrialización. Más concretamente, la reducción de los costes se articularía mediante las siguientes vías: modificación del sistema de labores subterráneas; instalación de nuevos hornos de fundición del mineral; introducción de máquinas que redujeran la dependencia respecto del trabajo humano para la realización de ciertas tareas; cambio de las ordenanzas que garantizase la primacía de la dirección técnica sobre la dirección «política» y la efectiva subordinación del personal de vigilancia y del resto de los trabajadores; liberalización de las relaciones laborales que acabara con las prácticas de reparto equitativo del trabajo entre todos los concurrentes a las Minas y de protección institucional de la «economía orgánica» de los mineros; reducción de las diversas faenas que demandaban «jornales de saneamiento».

Como vemos, el proyecto "moderno", sin abandonar la esfera técnicoeconómica, acaba incluyendo soluciones a problemas idénticos a los abordados por Ortuño y Parés y Franqués. Aspectos sociales, como son el orden productivo y la «economía orgánica», vuelven a ocupar un lugar destacado en la obra de unos ingenieros que representan fielmente la actitud intelectual dominante durante buena parte del siglo XIX hacia las relaciones entre producción, hombres y Naturaleza. Así, mientras que hasta 1850 la argumentación respecto a esos aspectos sociales se apoya en consideraciones éticas - $\mathrm{Pa}$ rés y Franqués- o jurídico-políticas —Ortuño- y se agota en sí misma, después se sustentará en la economía y la ciencia y perseguirá fines más amplios.

Aunque los ejemplos son abundantes, comenzaremos por dos de los pro-

3s Bernáldez y Rúa (1862), pp. 125 y 126. 
blemas más debatidos: la bajada y subida de los mineros y la ventilación de las minas.

Mientras que, en la segunda mitad del siglo xviII, Soler - -superintendente de las Minas- y Parés y Franqués tan sólo podían lamentarse o insistir en la construcción de «descansillos» entre tramo y tramo de escaleras de los pozos fundamentales, para evitar las frecuentes y peligrosas caídas, SánchezMolero escribía lo siguiente:

... de modo que en una entrada de seis horas para llegar al sitio de trabajo cuando éste está en el octavo o noveno piso y para salir a la superficie se consume inútilmente el 20,83 por ciento de duración del jornal y una gran parte de la fuerza muscular. Esta fatiga que en todos casos es muy perniciosa a la salud, tiene en Almadén peores consecuencias, porque aún antes de emprender los hombres su trabajo se encuentran ya predispuestos a recibir las emociones o vapores mercuriales. Por otra parte, tanta fatiga y tardanza para penetrar en la mina imposibilita la debida vigilancia en las operaciones y hace indispensable además la asistencia en todos los pisos en disfrute de cuarto o almacenes de herramientas para proveer de ellas a los operarios, ya al empezar el jornal ya cuando en el curso de él por accidentes naturales tienen que reponerla o cambiarla. El aumento de gasto que ocasiona el sistema actual de subida y bajada es ciertamente incalculable, y de seguro que al año representará por lo menos una cantidad de $250.000 \mathrm{rs}$. incluyendo la reparación de escalas, descansillo e importe de los dos cuartos de herramientas, pues respecto al precio a que se pagan los jornales tenemos el dato de que, en sitios de excavación por contrata y de una regular dureza se abonan a razón de 9 rs. libres, refiriéndose al quinto piso; 10 rs. para el sexto piso; 11 para el séptimo, octavo y noveno piso; hasta 13 rs. por bajo del noveno, y 14 en las profundidades. Se ve, pues, que entra por mucho en el precio del trabajo, la penalidad del tránsito por el interior y se comprende que ganando de continuo en profundidad, llegará día, no muy remoto, en que este aumento en el jornal sobrepuje al precio que tendría el jornal mismo, y al mismo tiempo, que ya no sea dado trabajar más que a gente muy joven capaz de resistir tal fatiga, la cual unida a la insalubridad de la mina haría más corta y desgraciada la vida de aquellos infelices. La humanidad y la economía reclaman, pues, 
que la entrada y salida de operarios se haga con auxilio de una máquina... ${ }^{36}$.

Donde antes no había sino buenos deseos y limitaciones técnicas, ahora, desaparecidas estas últimas, hallamos cálculo económico y capacidad tecnológica. Bernáldez y Rúa coincidirían en la conveniencia, basada en idénticas razones, de instalar un ascensor, denominado fabrkunst, que estaba siendo empleado con éxito en minas extranjeras.

Si cabe, el segundo ejemplo es más ilustrativo. En contraposición a los que, ya en 1778 , sostenían que la deficiente ventilación de las minas, conse. cuencia del inadecuado sistema de laboreo, constituía una de las causas básicas de la intoxicación de los trabajadores - tesis defendida por el alemán Hoppensac, director de las Minas, que puede ser considerado como el primer representante del discurso «moderno» que venimos comentando-, Parés y Franqués juzgaba:

... ser totalmente voluntario el pensamiento de ser el estado morboso de este mineraje, hijo meramente de la organización actual de nuestras minas; [...] es evidente provenir única y esencialmente de la varia exhalación, y sucedentes mociones minerales, con que la región subterránea infecciona el ambiente, que respiran los operarios... ${ }^{37}$.

Así, para Parés y Franqués, la única solución posible consistía en que los mineros

... se retiren enteramente de las ocasiones de percibir los efluvios minerales, solicitando aires campesinos nada impregnados de aquellos corpúsculos. y eligiéndose una dieta lacticinosa... ${ }^{38}$.

La solución propuesta poco añade a lo que en Almadén se conocía empíricamente. Por un lado, como él mismo reconoce, era válida tan sólo para los que se encontraban «al principio de ese mal». Por otro lado, esa «retirada al campo» era la respuesta adoptada desde antiguo por las autoridades y los mineros para lograr la reproducción de la fuerza de trabajo. En verano, época en que la entrada en las minas resultaba especialmente dañina a causa de los problemas adicionales con que tropezaba la ventilación, las actividades se reducían al mínimo. Así, durante la temporada estival - también en otras, pero

${ }^{36}$ Sánchez-Molero y Lletget (1857), tomo VII, p. 267.

37 Parés y Franqués, op. cit., p. 31 .

31 Ibidem, p. 46. 
menos intensamente- el empleo en la agricultura permitía la recuperación de la «economía orgánica» y la subsistencia de los trabajadores.

Años más tarde, los ingenieros Bernáldez y Rúa se enfrentaron al problema de manera diferente. Ellos, aceptando por fuerza la innegable toxicidad intrínseca al proceso productivo del mercurio, están persuadidos de la existencia de posibilidades ciertas para la intervención beneficiosa del hombre a través de la reforma del sistema de laboreo. Esto es, si bien existía un límite objetivo a la mejora de las condiciones interiores de las minas, éste distaba mucho de haber sido alcanzado en 1861 :

En otro lugar indicamos ya la mala ventilación de las Minas de Almadén, reconociendo, como causa principal, el sistema de laboreo empleado que pone grandes superficies al descubierto, siendo imposible llegue la corriente de aire a todos los puntos con la velocidad conveniente, sobre todo, cuando se trata de arrastrar los vapores mercuriales, cuyos funestos resultados sobre la economía de los obreros son bien conocidos ${ }^{39}$.

Sánchez-Molero, una vez más, argumenta en términos similares, no olvidándose de citar las implicaciones económicas del problema:

.. la ventilación en el día está muy lejos de ser lo perfecta que debiera para disminuir todo lo posible los perniciosos y eficaces efectos de las emanaciones mercuriales sobre la economía animal, y que por tanto conviene mejorarla hasta el grado de mayor perfección, no sólo por lo que la humanidad exige, sino también para castigar los gastos que se originan a consecuencia de lo que padece la salud de los obreros en el trabajo de esta clase de minas... ${ }^{40}$

Al igual que en el caso de la subida y bajada de los trabajadores, no existen dudas respecto a las posibilidades de mejorar la ventilación. Ello se conseguiría tras la reforma general del sistema de labores $o$, en otras palabras, la reordenación racional del espacio productivo, que permitiría una más activa circulación del aire a través de los pozos y galerías. Conseguidos ambos objetivos, los sentimientos humanitarios se verían satisfechos por la reducción de los sacrificios humanos exigidos por el proceso productivo. Pero, sobre todo, gracias a un aumento del tiempo de trabajo efectivo dentro de las minas, a la disminución de los gastos asistenciales (curación de heridos y enfer-

39 Bernáldez y Rua (1861), p. 183.

*1 Sánchez-Molero y Lletget (1858), tomo IX, p. 19. 
mos, «jornales de saneamiento», limosnas, pensiones, etc.) y a la desaparición de las limitaciones al número de entradas semanales, se conseguiría una reducción del componente salarial, directo e indirecto, de los gastos de explotación:

La disminución de gastos en los trabajos de minas a consecuencia de la mejor ventilación y de la más cómoda y pronta subida y bajada de la gente vienen a refluir principalmente en beneficio del arranque de minerales, que se conseguiría a un precio más módico... ${ }^{41}$.

Tampoco resulta difícil detectar el objetivo disciplinario de las memorias de estos ingenieros, especialmente en la de Bernáldez y Rúa. Su contribución al logro de un nuevo orden productivo consiste en una constante reivindicación de la figura de los detentadores de saber técnico: los ingenieros, también denominados facultativos. Refiriéndose a las dificultades que éstos encontraban en su labor cotidiana:

... es imposible la acción facultativa, rodeada por todas partes de escollos en donde zozobra la voluntad más firme, la razón más ilustrada. Arriba la oposición sistemática, la incompetencia o la inercia; abajo la insubordinación, el aconchavamiento, el opeyo empírico ${ }^{42}$.

Preso entre un «arriba» - la superintendencia_, apegado a unos criterios preindustriales, y un «abajo» - personal de vigilancia y trabajadores-, impregnado de unos valores y de unas necesidades — «economía moral»- no más favorables al orden productivo propugnado por los ingenieros, resulta imposible el triunfo de su proyecto:

La antorcha de la razón y del progreso que lleva en sus manos la generación del siglo xIx, no puede iluminar por más tiempo ese vergonzoso anacronismo, elocuente patrón de nuestra incuria que hace 60 años permanece olvidado entre las incultas montañas de nuestra Sierra Morena ${ }^{43}$.

Concedido el poder a los portadores de la razón y el progreso, la rentabilidad económica y el bienestar social estarían garantizados. Sin necesidad de mayores esfuerzos, la historia de la minería moderna basta para demostrar la

4. Ibidem, p. 20.

Bernáldez y Rua (1861), p. 126.

43 Ibidem, p. 267. 
falacia que conlleva esa idea de neutralidad de la razón instrumental y del progreso productivista. Idea falaz que oculta el contenido real de proyecto "progresista», perseguido tanto por los manufactureros británicos como por los planificadores soviéticos.

\section{Conclusión}

En el transcurso de un siglo, el que transcurre entre 1760 y 1860 , la actitud intelectual hacia los aspectos sociales del proceso productivo desarrollado en las Minas de Almadén experimentó un cambio profundo, en virtud del cual la tradicional aceptación de las condiciones técnico-económicas que presidían el cotidiano enfrentamiento del hombre con los recursos naturales es suplantada por un espíritu renovador, consciente de las nuevas posibilidades puestas al servicio de la producción por el progreso tecnológico.

Los representantes del «pensamiento antiguo» reflejan la búsqueda de soluciones a los costes y exigencias sociales de un proceso productivo complejo por parte de una sociedad incapaz de modificar las características fundamentales del mismo. Parés y Franqués expondrá su preocupación por la salud física y moral de los mineros, así como los remedios disponibles para la curación de ambos tipos de mal, si bien reconociendo sus grandes limitaciones a tal fin. Por su parte, Ortuño pretende contribuir a la consecución del factor humano necesitado por un orden productivo carente de mecanismos satisfactorios para controlar eficazmente el proceso de trabajo. Para ello, intentará reducir el recurso a instrumentos coercitivos exteriores a las conciencias mediante la intensificación de un discurso religioso destinado a lograr la interiorización de la disciplina por los mineros.

En cuanto a los exponentes del «pensamiento mcderno», éstos comenzaron señalando la inviabilidad del modelo de explotación seguido en las Minas. Su proyecto de reforma, basado en la introducción de maquinaria moderna y en la reordenación del espacio productivo, perseguirá la reducción del papel desempeñado por el hombre en el proceso productivo $\mathrm{y}$, consecuentemente, traerá consigo una disminución de los costes sociales. Las menores necesidades de vigilancia y la mejoría del estado sanitario serían un subproducto de la recuperación de la competitividad internacional de las Minas.

Así, pues, el cambio de óptica a la hora de enjuiciar esos aspectos sociales reproduciría la mutación sufrida por las relaciones de los seres humanos, entre sí y con la Naturaleza, a causa de las transformaciones económicas y sociales de amplio alcance que, iniciadas en Gran Bretaña, se expandieron, a través del comercio exterior, la movilidad del capital, la transferencia de tec- 
nología y la exportación de valores e ideas, al resto del mundo occidental, dando origen a las sociedades industrializadas.

Los temas aquí tratados guardan una estrecha conexión con las polémicas del presente. Mucho más próximos a Bernáldez, Rúa y Sánchez-Molero que a Parés y Franqués y Ortuño, difícilmente podemos conceder nuestra aprobación a la sociedad que produjo las diversas manifestaciones del «pensamiento antiguo». Sin embargo, una mirada a nuestro alrededor hoy, cuando el futuro de la especie humana está comprometido hasta un punto nunca antes imaginado, basta para disipar cualquier complacencia respecto a ese cercano «pensamiento moderno" en el cual hunde sus raíces nuestra cultura actual. Enfrentados a problemas tan acuciantes como son el hambre, la pobreza, el crecimiento demográfico, el despilfarro sistemático de recursos irrenovables, la degradación del ecosistema, el armamentismo y la amenaza de guerra nuclear, no puede sino sorprendernos que la ideología del progrès technique, progrès social: même combat haya podido ser considerada como una fuerza necesariamente liberadora de la humanidad.

\section{BIBLIOGRAFIA}

Bernaldez, Fernando, y Rúa Figueroa, Ramón (1861): Memoria sobre las Minas de Almadén y Almadenejos, Madrid.

Bernáldez, Fernando, y Rúa Figueroa, Ramón (1862): Reseña sobre la bistoria, la administración y la producción de las Minas de Almadén y Almadenejos, Madrid.

Cabanillas y Malo, Rafael (1838): «Memoria sobre Almadén», Anales de Minas, tomo I, Madrid, pp. 399-447.

Dobado, Rafael (1982): «Salarios y condiciones de trabajo en las Minas de Almadén», en TEDde, Pedro (ed.): La economía española al final del Antiguo Régimen, tomo II: Manufacturas, pp. 339-440.

FoucaulT, Michel (1981): Vigilar y castigar, Madrid, Siglo XXI.

Gaudemar, Jean Paul de (1981a): "La crisis como laboratorio social: el ejemplo de las disciplinas industriales», en AGLIETA, Amin et al.: Rupturas de un sistema económico, Madrid, H. Blume, pp. 214-262.

Gaudemar, Jean Paul de (1981b): «Preliminares para una genealogía de las formas de disciplinas, en Foucault et al.: Espacios de poder, Madrid, Las Ediciones de la Piqueta, pp. 85-121.

GÓMEZ DE FIGUEROA, Ricardo (1888): Estudio clínico de las entermedades que padecen los obreros de las Minas de Almadén, Madrid.

Hoppensack, Juan Martín, citado en Larruga, Eugenio (1792): Memorias políticas y económicas sobre los frutos, comercio, fábricas y minas de España, tomo XVII, Madrid, pp. 103-251.

Madoz, Pascual (1845): Diccionario Geográfico Estadístico de España, tomo II, Madrid, pp. 16-48.

MARGLIN, Stephen (1977): «Origenes y funciones de la parcelación de tareas. ¿Para qué sirven los patrones?», en GoRz, André (ed.): Crítica de la división del trabajo, Barcelona, Laia, pp. $45-96$.

Morete de VARELA, José (1857): «Descripción general de Almadén, Almadenejos, minas y demás de su territorio», Revista Minera, tomo VIII, Madrid, pp. $338-352$ y 370-384. 
Ortuño, Clemente José de (1804): Plan de un nuevo gobierno eclesiástico necesario y provechoso a la Villa de Almadén e intereses del Rey.

PARÉS y FRANQués, José (1778): Catástrophe morboso de las Minas Mercuriales de la Villa de Almadén del Azogue.

Prado, Casiano de (1848): Minas de Almadén, de las vicisitudes que ban pasado desde la Guerra de Independencia, y particularmente de los adelantos obtenidos en su conservación y fomento mientras estuvieran a cargo del Ingeniero Don Casiano de Prado, autor de esta memoria, Madrid.

SánC H EZ-Aparicio, Gervasio (1858): «Apuntes sobre las enfermedades de los mineros de Almadén», Revista Minera, tomos VII, VIII, IX y X, Madrid.

SÁnc H EZ-Molero y Lletget, Luis María (1856, 1857, 1858, 1859): «Memoria sobre azogues», Revista Minera, tomos VII, VIII, IX y X.

ThOMPSON, E. P. (1979): “La economía moral de la multitud», en Tradición, revuelta $y$ consciencia de clase, Barcelona, Crítica, pp. 62-134. 